Байкальский государственный университет, г. Иркутск, Российская Федерация

Е. В. Чигрина

Байкальский государственный университет, г. Иркутск, Российкая Федераиия

\title{
НЕДОПУСТИМОСТЬ ПРОИЗВОЛЬНОГО ВМЕШАТЕЛЬСТВА В ДЕЛА СЕМЬИ ГОСУДАРСТВЕННЫХ ОРГАНОВ И ДОЛЖНОСТНЫХ ЛИЦ ЧЕРЕЗ ПРИЗМУ СОЦИАЛЬНОГО ПАТРОНАТА
}

\begin{abstract}
АНнотАЦия. В статье предпринята попытка исследования особой формы вмешательства государства в дела семьи - так называемый социальный патронат. Акцент делается на том, что возможность осуществления защиты интересов своих детей должна быть предоставлена, в первую очередь, законным представителям, поскольку сохранение их особой связи имеет естественно-правовое значение. В силу ст. 55 Конституции РФ и ст. 1 Гражданского кодекса РФ ограничение прав граждан возможно лишь только в той мере, в какой это необходимо в целях защиты основ конституционного строя, нравственности, здоровья, прав и законных интересов других лиц, обеспечения обороны страны и безопасности государства. Отвечающие этой мере способы правового воздействия на родителей ребенка, допускающих нарушение или угрозу нарушения его прав, в достаточной степени присутствуют в действующем семейном законодательстве, а также представлены в большей или меньшей степени удачно в законодательстве об административных правонарушениях. Дополнительное ограничение прав родителей при таких обстоятельствах создает угрозу произвольного вмешательства кого-либо в дела семьи и разрушения семейных ценностей. Авторы считают более приемлемым использование публично-правовых механизмов, чем выстраивание системы превентивного реагирования на ситуации, создающие потенциальную угрозу нарушения интересов семьи.

кЛЮчЕВЫЕ СЛОВА. Брак; семья; государство; институт социального патроната; социальное сопровождение; семейное законодательство.

ФИНАНСИРОВАНИЕ. Государственное задание Министерства образования и науки РФ в 2014-2016 гг. № 29.1247.2014/К на выполнение научно-исследовательских работ в сфере научной деятельности в рамках проектной части, проект № 1247 «Пределы ограничения прав личности в уголовном судопроизводстве в целях обеспечения национальной безопасности государства: уголовно-процессуальный и криминалистический анализ».
\end{abstract}

ИНФОРМАЦИЯ О СТАТЬЕ. Дата поступления 11 апреля 2016 г.; дата принятия к печати 27 мая 2016 г.; дата онлайн-размещения 29 июля 2016 г.

S. V. Kornakova Baikal State University, Irkutsk, Russian Federation E. V. Chigrina

Baikal State University, Irkutsk, Russian Federation

\section{INADMISSIBILITY OF ARBITRARY INTERFERENCE IN FAMILY AFFAIRS BY GOVERNMENTAL AGENCIES AND OFFICIALS THROUGH THE PRISM OF SOCIAL PATRONAGE}

ABSTRACT. The article makes an attempt to study a special form of governmental interference in family affairs - the so-called social patronage. It emphasizes the fact that the possibility of implementing the protection of their children' interests must be granted, in the first place, to legal representatives, because preservation of their special relationship is of natural-legal importance. By virtue of Article 55 of the RF Constitution and Article 1 of the RF Civil Code, restriction of citizens ' rights is possible only to the extent that this

\section{Baikal Research Journal}


is necessary in order to protect the foundations of the constitutional system, morality, health, rights and lawful interests of other persons, to provide national defense and state security. The methods of legal influence on the child's parents that meet this measure, permitting violation or threat of violation of his or her rights, are sufficiently presented in the existing family legislation, and are also represented, successfully to a greater or lesser extent, in the administrative offence legislation. Further limitation of the parents' rights under such circumstances creates a threat of someone's arbitrary interference in the family affairs and destruction of family values. The authors believe that using public and law mechanisms is more appropriate than building a system of preventive response to situations that create a potential threat of violating family's interests.

KEYWORDS. Marriage; family; government; institute of social patronage; social support; family law legislation.

FINANCING. Governmental order No. 29.1247.2014/ $K$ on performance of work in the field of scientific activities within the framework of the project No. 1247 «The limits of individual rights in criminal proceedings in order to ensure national security: criminal procedure and forensic analysis» (registration No. 114091140016 in FGANU TsITiS). ARTICLE INFO. Received April 11, 2016; accepted May 27, 2016; available online July 29, 2016.

В семейно-правовой науке бытуют различные подходы к пониманию брака. Так, А. И. Загоровский в браке выделял следующие элементы:

- естественный или физический - физиологическое влечение представителей разного пола друг к другу, обусловленное природой человека;

- этический - взаимная нравственная привязанность супругов, общность их внутреннего, духовного мира;

- экономический - связь, в силу которой возникает общее хозяйство мужа и жены;

- юридический - определенное юридическое положение лиц, взаимно связанных супружеством, порождающее для них взаимные права и обязанности;

- религиозный - подчинение брака правилам религии [1, с. 6].

По мнению Н. Н. Тарусиной, понятие «брак» можно определить, во-первых, как таинство, во-вторых, как договор и, в-третьих, как особого рода институт [2, с. 72 ].

В своем исследовании брака славян дохристианской эпохи М. И. Горчаков обратил внимание на то, что «вступление в брак у языческих славян имело две составляющие: следование законам природы и служение божеству». Это позволило ему дать следующую дефиницию брака - это «взаимное понятие мужчины и женщины для осуществления ими полового закона природы, для служения божеству Яриле, для совместного сожития и семейного счастья в течении всей их жизни» [3, с. 18]. В толковом словаре русского языка С. И. Ожегова под браком понимаются «супружеские отношения, законно оформленные» [4, с. 55].

По нашему мнению, брак - это социально-правовое явление, представляющее собой законно оформленный союз между мужчиной и женщиной, заключенный в целях совместного проживания, ведения общего хозяйства, рождения и воспитания детей.

Таким образом, семья - это сложное социокультурное явление, уникальность и специфика которого в том и состоит, что семья фокусирует в себе практически все аспекты жизни человека, выходя на все уровни его социальной практики: от материального до духовного, от индивидуального до общественно-исторического. При этом сущность и значение семьи состоит не просто в воспроизводстве населения, а в том, что семья выступает связующим звеном поколений рода. Именно в памяти рода, в его вере семья обретает бессмертие. В народном сознании древнерусского человека род (родственники, семья, племя), народ, Родина были связаны не просто однокоренными словами, но и отражали специфику миропонимания, идею развития общества. Русское православие усиливает духовное содержание рода и семьи. Семья выступает не только социальным сообществом супругов, родителей и детей, но и ду-

\section{Baikal Research Journal}


ховной ячейкой, «малой церковью». Такой подход к рассматриваемому институту позволяет видеть не частные проявления проблем семьи, а акцентировать внимание на ее развитии в контексте того социума, из которого она вырастает [5, с. 7].

В настоящее время в России критерием ослабления института семьи является высокий уровень социального сиротства. Необходимо создать механизм социального сопровождения как кровных, так и замещающих семей, оказавшихся в трудной жизненной ситуации, тем самым сводя к минимуму случаи устройства детей в организации для детей-сирот и детей, оставшихся без попечения родителей, вследствие расторжения договора о передаче ребенка на воспитание в приемную семью, на патронатное воспитание, отмены усыновления. Очень важно обеспечить каждому ребенку право жить и воспитываться в семье [6, с. 396-397].

28 декабря 2012 г. вышел Указ Президента РФ «О некоторых мерах по реализации государственной политики в сфере защиты детей-сирот и детей, оставшихся без попечения родителей» от 28 декабря 2012 г. № 1688 (далее - Указ № 1688). Согласно п. 2 Указа № 1688 Государственной Думе Федерального Собрания РФ рекомендовано «доработать в приоритетном порядке проекты Федерального закона “Об общественном контроле за обеспечением прав детей-сирот и детей, оставшихся без попечения родителей” и Федерального закона “О внесении изменений в отдельные законодательные акты Российской Федерации по вопросам осуществления социального патроната и деятельности органов опеки и попечительства" ", предусмотрев, в частности, уточнение порядка приема ребенка в патронатную семью и формы его воспитания.

В п. 6 Указа № 1688 предписывается: «Внести в перечень показателей для оценки эффективности деятельности органов исполнительной власти субъектов Российской Федерации, утвержденный Указом Президента Российской Федерации от 21 августа 2012 г. № 1199 “Об оценке эффективности органов исполнительной власти субъектов Российской Федерации”, изменение, дополнив его пунктом 12 следующего содержания: «Доля детей, оставшихся без попечения родителей, - ... всего, в том числе переданных не родственникам (в приемные семьи, на усыновление (удочерение), под опеку (попечительство), охваченных другими факторами семейного устройства (семейные детские дома, патронатные семьи), находящихся в государственных (муниципальных) учреждениях всех типов» .

Ежегодно в России исключительно по усмотрению органов опеки и попечительства производится около $94 \%$ случаев изъятия детей из семей, $90 \%$ случаев лишения родительских прав и 80 \% случаев ограничения в родительских правах. Следует подчеркнуть, что усмотрение указанных органов, в первую очередь, зависит от того, каким образом ими толкуются термины «невыполнение или ненадлежащее выполнение родительских обязанностей по воспитанию, обучению и содержанию детей», «ребенок, находящийся в социально опасном положении», «семья, находящаяся в социально опасном положении», «злоупотребление со стороны родителей» и т. д.

Важно отметить, что само по себе наличие в семье несовершеннолетнего ребенка является достаточным основанием для вмешательства, нередко бесцеремонного, представителей органов опеки и попечительства, а также органов внутренних дел во внутренние дела семьи, проникновения в жилище, для постановки семьи на учет как находящейся в социально опасном положении, и контроля за такой семьей, в том числе с применением мер индивидуальной профилактической работы и с детьми, и с их родителями.

Названный Указ вступил в силу с 1 января 2013 г. В этом же году Государственная Дума РФ приступила к разработке законопроекта «О социальном патронате», который вызвал широкое публичное обсуждение и общественный резонанс. В вину разработчикам проекта ставились нечеткие формулировки, не в должной мере определенные основания, на которых семья может быть признана находящейся

\section{Baikal Research Journal}

электронный научный журнал Байкальского государственного университета 
«в социально опасном положении». Полагаем, что подобная практика основана на противоречивости семейного законодательства. В общественном сознании названный законопроект ассоциировался с «ювенальной юстицией». Поэтому задача законодательства с одной стороны, а с другой - воспитания и образования состоит в том, чтобы устанавливать и поддерживать как можно большее соответствие между законодательным правом и правовым чувством солидарности с принимаемыми в государстве законами как можно большего числа граждан государства [7, с. 130].

Хорошо известно, что для гражданского общества важна независимость граждан, которая заключается в их реальной возможности существовать самостоятельно, реализовывать свои частные интересы и потребности $[8$, с. 6$]$, в том числе и в сфере семейного воспитания. В этой связи П. А. Юсов совершенно обоснованно замечает, что в правовом отношении вмешательство государства в воспитательный процесс детей в семье характеризуется некоторыми противоречиями. Так, если с одной стороны, государство при помощи права пытается взять детей под опеку, запрещая применение к ним физических или приравненных к ним наказаний со стороны родителей, то с другой, само государство предъявляет претензии к родителям по поводу непослушания, невоспитанности, избалованности или грубости детей. Государство не совсем правильно понимает и нормообосновывает правовую безответственность несовершеннолетних. По мнению указанного автора, несовершеннолетние должны понимать свою зависимость от родителей, осознавать свое фактическое неравенство по отношению к любому взрослому человеку. Это означает, что дети должны принимать как аксиому, что любая провинность с необходимостью влечет соответствующую ей ответственность. Детей нужно наказывать и, может быть, даже очень строго в том числе физически, но при непременном условии, что наказание следует лишь за действительную провинность и соответствует ее границам [9, с. 126-127].

Представляется, что такой точки зрения придерживается большинство родителей, в том числе и авторы данной статьи. Именно в связи с наличием у российских граждан подобных взглядов произвольное вмешательство чиновников во внутренние дела семьи вызывает общественный протест. С точки зрения представителей общественности, подобные государственные меры открывают возможность для произвола социальных служб, а также для увеличения вероятности и количества случаев безосновательного изъятия детей из семьи и размещения их в детских домах.

21 января 2014 г. вызвавший беспокойство общественности законопроект «О социальном патронате» был рассмотрен во втором чтении и отклонен Государственной Думой РФ. Казалось бы, принято правильное решение и оснований для тревог больше нет. Тем не менее, пока внимание общественности было приковано к патронату, Государственной Думой РФ был принят Федеральный закон «Об основах социального обслуживания граждан в Российской Федерации», вступивший в силу с января 2015 г.

Волну обеспокоенности вызвала ст. 22 указанного закона, и если он не будет изменен, то позволит органам опеки беспрепятственно вмешиваться в жизнь семьи теперь уже под предлогом «социального сопровождения». Такого мнения, в частности, придерживается глава Ассоциации родительских комитетов и сообществ О. Леткова. Так, указанным автором отмечается, что под «социальным сопровождением» подразумевается «содействие в предоставлении медицинской, психологической, педагогической, юридической, социальной помощи, не относящейся к социальным услугам». Казалось бы, звучит вполне безобидно, если не знать о так называемом «регламенте межведомственного взаимодействия», который регулируется предоставлением социального сопровождения. «Этот регламент по сути - соглашение всех органов, которые занимаются защитой прав детей, - уточняет О. Леткова. И при любом сигнале о семейном неблагополучии в конкретную семью тут же должны прийти социальные работники и проверить условия содержания ребенка, чтобы

\section{Baikal Research Journal}

электронный научный журнал Байкальского государственного университета 
выдать план исправления недостатков. Но если семья не соглашается с ними, ребенок изымается из семьи» [10]. При этом поводом могут стать наличие у ребенка синяков, насморка, его гиперактивности, развод родителей, многодетность и т. д.

Можно предположить, что пресловутая «ювенальная система» будет узаконена. Основополагающим моментом этого законодательного акта должна быть добровольность родителей на принятие от государства социальных услуг.

Однако при внимательном рассмотрении ст. 14 настоящего Федерального закона становится очевидным, что заявление о социальном обслуживании (за которым, по мнению социальных структур, может последовать и социальное сопровождение) может подать не только сам человек, в нем нуждающийся, но и любая общественная, коммерческая или государственная организация, и оно будет рассмотрено соответствующими органами. Более того, ст. 22 названного закона имеет противоречащий ранее изложенному характер, поскольку в ней указано, что социальное сопровождение не относится к социальным услугам и добровольность на него не распространяется.

Юрист правовой группы Центра лечебной педагогики Е. Заблоцкис отмечает, что независимо от того, кто обратился по поводу социального обслуживания, согласие самого гражданина обязательно. Закон не вводит ситуаций «принудительной помощи» [11]. При этом вводятся новые (в сравнении с прежним законом) основания для признания гражданина нуждающимся в социальном обслуживании: наличие в семье ребенка-инвалида, нуждающегося в постоянном уходе; отсутствие возможности обеспечения ухода за инвалидом, ребенком; наличие ребенка, испытывающего трудности в социальной адаптации; наличие внутрисемейного конфликта, в том числе с лицами, имеющими наркотическую или алкогольную зависимость, имеющими пристрастие к азартным играм или с психическими расстройствами; наличие насилия в семье.

В социальное обслуживание входит, помимо социальных услуг, также содействие в предоставлении медицинской, психологической, педагогической, юридической, социальной помощи, не относящимся непосредственно к социальным услугам. Такое выделение полезно с точки зрения обеспечения «комплексности» помощи. В связи с этим заметим, что в прежнем законодательстве это также находило отражение, но предусматривалось в составе социальных услуг. Безусловно, с формальной точки зрения новый подход предпочтительнее, поскольку органы социальной защиты отныне обязаны будут включаться в межведомственное взаимодействие, в частности, отсылать первичные письма в соответствующие ведомства.

На наш взгляд, представляет несомненный интерес исследование А. З. Дзугаевой, с точки зрения которой одной из основных форм профилактической работы должно быть осуществление социального патроната над семьей на добровольной основе в целях повышения родительской ответственности и сохранения ребенка в его родной семье. Социальный патронат регулируется законодательством г. Москвы и осуществляется на основании договора, заключенного между уполномоченным органом в сфере опеки, попечительства и патронажа, уполномоченной организацией и законным представителем (представителями) ребенка (детей) в целях реабилитации семьи.

Вместе с тем, потенциал института социального патроната в должной мере не реализован и для его работоспособности, по мнению указанного автора, целесообразно привлечение ресурсов негосударственных организаций. С этой целью разработан проект постановления правительства Москвы об утверждении порядка предоставления в 2014 г. субсидий из бюджета г. Москвы негосударственным организациям на осуществление работы по социальному патронату [12, с. 24].

Представляется, что организация системной профилактической и реабилитационной работы с семьями, имеющими детей, в данном формате позволит сократить количество изымаемых из семей детей, и числа родителей, ограниченных или лишенных родительских прав. Параллельно Минтруд России и субъект РФ должны

\section{Baikal Research Journal}

электронный научный журнал Байкальского государственного университета 
утвердить рекомендации по порядку организации межведомственного взаимодействия по предоставлению как непосредственно социальных услуг, так и описанных ранее услуг по «содействию».

В этом отношении может быть полезен опыт Иркутской области, где утверждено и действует «Положение о межведомственном взаимодействии органов государственной власти Иркутской области при организации социального обслуживания населения» . Документом предписано взаимодействие между Министерством социального развития, опеки и попечительства Иркутской области, Министерством здравоохранения Иркутской области, Министерством образования Иркутской области, Министерством труда и занятости Иркутской области, Министерством юстиции Иркутской области. Взаимодействие подразумевает обмен информацией, необходимой для реализации полномочий в сфере социального обслуживания граждан, предоставления социальных услуг и социального сопровождения, в том числе направление обращений в интересах граждан для рассмотрения вопроса о предоставлении социального обслуживания.

В заключении хотелось бы подчеркнуть, что крайне важно, чтобы в процессе принятия решений различного уровня не нарушался один из основополагающих принципов семейного права - невмешательство третьих лиц в дела семьи. Тем не менее, зачастую государственные интересы превалируют над интересами семьи и, что более важно, интересами несовершеннолетних детей.

\section{Список использованной литературы}

1. Загоровский А. И. Курс семейного права / А. И. Загоровский. - М. : Зерцало, 2003. - 464 с.

2. Тарусина Н. Н. Брак по российскому семейному праву : учеб. пособие / Н. Н. Тарусина. - Ярославль : Ярослав. гос. ун-т, 2007. - 254 с.

3. Александрова А. Ю. Понятие брака в российском правоведении XIX - начала ХХ века / А. Ю. Александрова // История государства и права. - 2008. — № 11. - С. $18-19$.

4. Ожегов С. И. Словарь русского языка / С. И. Ожегов. - 7-е изд. - М. : Сов. энцикл., 1968. $-900 \mathrm{c}$.

5. Концепция государственной семейной политики Российской Федерации на период до 2025 года (общественный проект) : в 3 ч. / сост. Е. Б. Мизулина [и др.]. — М., 2013. Ч. $1 .-26 \mathrm{c}$.

6. Проскурина Д. С. Проблема реализации прав ребенка / Д. С. Проскурина // 20 лет Конституции России: актуальные проблемы развития правового государства : сб. науч. тр. Иркутск : Изд-во БГУЭП, 2014. - С. 394-397.

7. Корнакова С. В. Правовая культура личности как условие эффективной реализации ее прав и свобод / С. В. Корнакова, Е. В. Чигрина // 20 лет Конституции России: актуальные проблемы развития правового государства : сб. науч. тр. - Иркутск : Изд-во БГУЭП, 2014. - С. 125-130.

8. Чигрина Е. В. Гражданская активность как фактор и условие институционализации структур гражданского общества / Е. В. Чигрина, Л. Н. Батьянова // Гражданин и право. 2010. - № 3. - С. 4-7.

9. Юсов П. А. Содержание и смысл права / П. А. Юсов. - Южно-Сахалинск : Сахалин. гос. Ун-т, 2011. - $188 \mathrm{c}$.

10. Леткова О. Закон о социальном обслуживании граждан: лучше прежнего [Электронный ресурс] / О. Леткова. - URL : http://www.osoboedetstvo.ru/post/2014/02/zakon-osocialnom-obsluzhivanii-grazhdan-luchshe-prezhnego.

11. Заблоцкис Е. Ю. Особые дети и взрослые в России: закон, правоприменение, взгляд в будущее. Основные проблемы и пути их решения / Е. Ю. Заблоцкис. - М. : Теревинф, 2013. - 368 c.

12. Дзугаева А. 3. Организация работы по профилактике социального сиротства и разрешению споров, связанных с воспитанием детей, в г. Москве / А. З. Дзугаева // Семейное и жилищное право. - 2014. - № 2. - С. 23-27.

\section{References}

1. Zagorovsky A. I. Kurs semeinogo prava [A Course of Family Law] Moscow, Zertsalo Publ., 2003. 464 p.

\section{Baikal Research Journal}


2. Tarusina N. N. Brak po rossiiskomu semeinomu pravu [Marriage according to the Russian Family Law]. Yaroslavl State University Publ., 2007. 254 p.

3. Aleksandrova A. Yu. Concept of marriage in Russian legal science in XIX-early XX centuries. Istoriya gosudarstva i prava = History of State and Law, 2008, no. 11, pp. 18-19. (In Russian).

4. Ozhegov S. I. Slovar russkogo yazyka [Dictionary of the Russian Language]. $7^{\text {th }}$ ed. Moscow, Sovetskaya entsiklopediya Publ., 1968. 900 p.

5. Mizulina E. B. et al. (eds). Kontseptsiya gosudarstvennoi semeinoi politiki Rossiiskoi Feder atsii na period do 2025 goda (obshchestvennyi proekt) [Concept of governmental family policy of the Russian Federation for the period till 2025 (public project). Moscow, 2013. Pr. 1. 26 p.

6. Proskurina D. S. Problems of implementing child's rights. 20 let Konstitutsii Rossii: aktual'nye problemy razvitiya pravovogo gosudarstva [20 years of the Constitution of Russia: topical problems of developing a legal state]. Irkutsk, Baikal State University Economics and Law Publ., 2014, pp. 394-397. (In Russian).

7. Kornakova S. V. Legal culture of the person as a condition of effective implementation of his or her rights and freedoms. 20 let Konstitutsii Rossii: aktual'nye problemy razvitiya pravovogo gosudarstva [20 years of the Constitution of Russia: topical problems of developing a legal state]. Irkutsk, Baikal State University Economics and Law Publ., 2014, pp. 125-130. (In Russian).

8. Chigrina E. V., Batyanova L. N. Social activeness as a factor and condition of institutionalizing the civil society. Grazhdanin $i$ pravo = Citizen and Law, 2010, no. 3, pp. 4-7. (In Russian).

9. Yusov P. A. Soderzhanie $i$ smysl prava [Content and tenor of law]. Yuzhno-Sakhalinsk, Sakhalin State University Publ., 2011. 188 p.

10. Letkova O. Zakon o sotsial'nom obsluzhivanii grazhdan: luchshe prezhnego [Law on social services for citizens: better than the previous one]. Available at: http://www.osoboedetstvo.ru/ post/2014/02/zakon-o-socialnom-obsluzhivanii-grazhdan-luchshe-prezhnego. (In Russian).

11. Zablotskis E. Yu. Osobye deti i vzroslye v Rossii: zakon, pravoprimenenie, vzglyad v budushchee. Osnovnye problemy $i$ puti ikh resheniya [Special children and adults in Russia: law, law enforcement, look into the future. Main problems and ways of their solution]. Moscow, Terevinf Publ., 2013. 368 p.

12. Dzugayeva A. Z. Organization of work on prophylactics of social orphanage and resolution of disputes related to upbringing of children in Moscow. Semeinoe $i$ zhilishchnoe pravo = Family and Housing Law, 2014, no. 2, pp. 23-27. (In Russian).

\section{Информация об авторах}

Корнакова Светлана Викторовна - кандидат юридических наук, доцент, доцент кафедры уголовного права, уголовного процесса и криминологии, Байкальский государственный университет, 664003, г. Иркутск, ул. Ленина, 11; e-mail: Svetlana-kornakova@yandex.ru.

Чигрина Елена Владимировна - кандидат экономических наук, доцент кафедры теории государства и права и социально-правовых дисциплин, Байкальский государственный университет, 664003, г. Иркутск, ул. Ленина, 11; e-mail: chigrina-ev@bgu.ru.

\section{Authors}

Svetlana V. Kornakova - PhD in Law, Associate Professor, Chair of Criminal Law, Criminal Procedure and Criminology, Baikal State University, 11 Lenin St., 664003, Irkutsk, Russian Federation; e-mail: Svetlana-kornakova@yandex.ru.

Elena V. Chigrina - PhD in Economics, Associate Professor, Chair of Theory of State and Law and Socio-Legal Disciplines, Baikal State University, 11 Lenin St., 664003, Irkutsk, Russian Federation; e-mail: chigrina-ev@bgu.ru.

\section{Библиографическое описание статьи}

Корнакова С. В. Недопустимость произвольного вмешательства в дела семьи государственных органов и должностных лиц через призму социального патроната / С. В. Корнакова, Е. В. Чигрина // Baikal Research Journal. - 2016. — T. 7, № 4. - DOI : 10.17150/2411$6262.2016 .7(4) .20$.

\section{Reference to article}

Kornakova S. V., Chigrina E. V. Inadmissibility of arbitrary interference in family affairs by governmental agencies and officials through the prism of social patronage. Baikal Research Journal, 2016, vol. 7, no. 4. DOI : 10.17150/2411-6262.2016.7(4).20. (In Russian).

\section{Baikal Research Journal}

